\title{
Short-term treatment effects produced by rapid maxillary expansion evaluated with computed tomography: A systematic review with meta-analysis
}

\author{
Antonino Lo Giudice ${ }^{\mathrm{a}}$ (1) \\ Paola Spinuzza ${ }^{\mathrm{b}}$ \\ Lorenzo Rustico ${ }^{b}$ \\ Gabriele Messina ${ }^{b}$ \\ Riccardo Nucera ${ }^{\mathrm{b}}$
}

${ }^{a}$ Department of Medical-Surgical Specialties, Section of Orthodontics, School of Dentistry, University of Catania, Policlinico Universitario V. Emanuele, Catania, Italy

${ }^{\mathrm{b}}$ Department of Biomedical and Dental Sciences and Morphofunctional lmaging, Section of Orthodontics, School of Dentistry, University of Messina, Policlinico Universitario G. Martino, Messina, Italy

\begin{abstract}
Objective: To identify the available evidence on the effects of rapid maxillary expansion (RME) with three-dimensional imaging and provide meta-analytic data from studies assessing the outcomes using computed tomography. Methods: Eleven electronic databases were searched, and prospective case series were selected. Two authors screened all titles and abstracts and assessed full texts of the remaining articles. Seventeen case series were included in the quantitative synthesis. Seven outcomes were investigated: nasal cavity width, maxillary basal bone width, alveolar buccal crest width, alveolar palatal crest width, inter-molar crown width, inter-molar root apex width, and buccopalatal molar inclination. The outcomes were investigated at two-time points: postexpansion (2-6 weeks) and post-retention (4-8 months). Mean differences and 95\% confidence intervals were used to summarize and combine the data. Results: All the investigated outcomes showed significant differences postexpansion (maxillary basal bone width, $+2.46 \mathrm{~mm}$; nasal cavity width, +1.95 $\mathrm{mm}$; alveolar buccal crest width, $+3.90 \mathrm{~mm}$; alveolar palatal crest width, +3.09 $\mathrm{mm}$; intermolar crown width, $+5.69 \mathrm{~mm}$; inter-molar root apex width, +2.85 $\mathrm{mm}$; and dental tipping, $+3.75^{\circ}$ ) and post-retention (maxillary basal bone width, $+2.21 \mathrm{~mm}$; nasal cavity width, $+1.55 \mathrm{~mm}$; alveolar buccal crest width, $+3.57 \mathrm{~mm}$; alveolar palatal crest width, $+3.32 \mathrm{~mm}$; inter-molar crown width, $+5.43 \mathrm{~mm}$; inter-molar root apex width, $+4.75 \mathrm{~mm}$; and dental tipping, $2.22^{\circ}$ ) compared to pre-expansion. Conclusions: After RME, skeletal expansion of the nasomaxillary complex was greater in most caudal structures. Maxillary basal bone showed 10\% post-retention relapse. During retention period, uprighting of maxillary molars occurred.
\end{abstract}

[Korean J Orthod 2020;50(5):314-323]

Key words: Rapid maxillary expansion, Computed tomography, Systematic review, Meta-analysis

Received March 20, 2020; Revised June 7, 2020; Accepted June 8, 2020.

Corresponding author: Antonino Lo Giudice.

Adjunct Professor, Department of Medical-Surgical Specialties, Section of Orthodontics, School of Dentistry, University of Catania, Policlinico Universitario V. Emanuele, Via Santa Sofia 78, Catania 95123, ltaly.

Tel+39-0953782475 e-mail nino.logiudice@gmail.com

How to cite this article: Lo Giudice A, Spinuzza P, Rustico L, Messina G, Nucera R. Short-term treatment effects produced by rapid maxillary expansion evaluated with computed tomography: A systematic review with meta-analysis. Korean J Orthod 2020;50:314-323.

(C) 2020 The Korean Association of Orthodontists.

This is an Open Access article distributed under the terms of the Creative Commons Attribution Non-Commercial License (http://creativecommons.org/licenses/by-nc/4.0) which permits unrestricted non-commercial use, distribution, and reproduction in any medium, provided the original work is properly cited. 


\section{INTRODUCTION}

Orthopedic palatal expansion treatment has been used for more than a century and a half to correct transverse maxillary deficiency. 'Orthopedic palatal expansion is usually prescribed when a transverse skeletal discrepancy is diagnosed; it promotes a combination of orthopedic, dental, and dentoalveolar treatment effects. ${ }^{2}$ The effects of orthopedic palatal expansion treatment are not limited to the maxilla; they extend to the surrounding maxillary structures. ${ }^{3,4}$ Different authors have investigated the effects of palatal expansion through twodimensional (2D) radiographic examinations. ${ }^{5}$ However, the superimposition of different anatomical structures on the radiographic film was found to potentially affect landmark identification in 2D imaging studies. ${ }^{6}$ In 1982, the use of computed tomography (CT) was proposed for three-dimensional (3D) evaluation of the basal bone changes induced by maxillary expansion. ${ }^{7}$ Literature showed that CT is a valid approach to evaluate, with greater accuracy, the modifications induced by orthopedic palatal expansion. ${ }^{8}$ In order to provide clinicians with useful information related to treatment effects and the potential side effects of this technique, numerous CT studies were performed to evaluate the effects of maxillary orthopedic expansion. ${ }^{9-26}$ Some systematic reviews with meta-analyses have been performed to evaluate the dentoskeletal effects induced by palatal expansion. ${ }^{27-29}$ However, these reviews were performed including only studies conducted with $2 \mathrm{D}$ radiographic techniques.

The aim of this systematic review with meta-analysis was to select the available evidence evaluating the effects of orthopedic palatal expansion with 3D imaging (cone-beam CT or low-dose CT) in order to provide meta-analytic data derived from studies assessing the 3D characteristics with the accuracy afforded by CT.

\section{MATERIALS AND METHODS}

\section{Protocol and registration}

This systematic review and meta-analysis was reported according to the guidelines provided by the Preferred Reporting ltems for Systematic Reviews and Meta-Analyses (PRISMA) statement. ${ }^{30}$ Unfortunately, the Cochrane Handbook for Systematic Reviews of Interventions does not provide guidelines for conducting systematic reviews when only case series are available.

The protocol of this review was registered on PROSPERO international prospective register of systematic reviews (PROSPERO 2017: CRD42017067362). http://www.crd.york.ac.uk/PROSPERO/display_record. asp?ID=CRD42017067362.

\section{Information sources and search}

A survey of articles published up to June 2019 about the dentoskeletal effects of rapid maxillary expansion (RME) evaluated with 3D radiographic imaging techniques was performed. Grey literature in electronic databases for conference abstracts, thesis dissertations, and unpublished literature was searched. No limitations concerning language, publication year, or publication status were applied. The following 12 electronic databases were searched: PubMed, OvidSP, ScienceDirect, Cochrane Database, Google Scholar, Web of Science, Scopus, LILACS, Evidence-Based Medicine, Conference Proceedings Citation Index, ClinicalTrials.gov, and International Clinical Trials Registry Platform.

\section{Eligibility criteria and selection of studies}

Studies were considered eligible if the study sample was prospectively enrolled or if it was a retrospective sample derived from a previous prospective trial. The studies were also included when they exhibited the following characteristics reported according the PICO format: studies conducted in growing human subjects (Participants); studies evaluating RME treatment effects (Intervention), assessing the status before and after palatal expansion with follow-up periods up to 8 months (Comparison), and studies assessing 3D cephalometric outcomes (Outcomes) obtained from CT exams (conebeam CT and low-dose multi-slice $\mathrm{CT}$ ) and reporting both dental and skeletal outcomes.

Articles were excluded if they did not meet the inclusion criteria, did not relate to this topic, or were related but had a different aim. Furthermore, studies including subjects with the following characteristics were excluded: congenital syndromes, periodontal diseases, or orofacial inflammatory conditions; studies assessing only skeletal or only dental values; studies involving boneborne palatal expander; and studies evaluating surgically assisted palatal expansion.

Two authors (P.S. and G.M.) deleted the duplicate reports, screened all titles and abstracts, and assessed the full texts of the remaining articles. The eligibility of the trials was evaluated independently, and any disagreement was resolved after consulting another author (R.N.). The level of agreement between the two reviewers was assessed by Cohen kappa statistics.

\section{Data collection process and extraction}

Two authors (A.L.G. and L.R.) independently extracted study characteristics (study design, type of appliance, sample size, age, sex, setting, observation period, time of daily activation) and outcomes from the selected studies by using predefined data extraction forms. Any disagreements were resolved by discussion with another author (R.N.). Cohen kappa statistics were used to assess 
the agreement between the two authors.

\section{Summary measures and data analysis}

This review was conducted by including case series in the final study selection. For ethical reasons, the majority of studies evaluating palatal expansion by means of CT used a case series design without a control group. This study design is considered appropriate to evaluate the effects of palatal expansion procedures because the maxillary growth in the considered time interval (up to 8 months) can be considered negligible. ${ }^{31}$ Literature showed that when clinical trials with untreated control groups are not available, case series without control groups can be used to perform meta-analyses. ${ }^{32-34}$

The mean differences (MDs) and their corresponding 95\% confidence intervals (95\% Cls) were used to summarize and combine data for each continuous outcome under investigation. Random-effects models were applied to estimate all pooled data. Meta-analyses were performed with Stata software (StataCorp, 2016 Stata statistical software, release 14.1, College Station, TX, USA) using the "metan" command.

\section{Assessment of risk of bias and sensitivity analysis}

Two authors (P.S. and G.M.) independently investigated any potential sources of bias and the quality of reporting by using a tool for risk of bias assessment developed by Guo et al. ${ }^{35}$ that uses a modified Delphi technique. The Moga's tool for quality appraisal checklist is the gold standard for evaluation of bias in case series; it consists of 19 questions evaluating eight primary domains from case series, i.e., study objective, study design, population, intervention and co-intervention(s), outcome measures, statistical analysis, results and conclusions, and competing interests and sources of financial support. We used Moga's tool, scoring each answer and assigning two points in case the answer reflected a low risk of bias or 0 points if the answer reflected a high risk of bias. Application of this methodology to each evaluated study could yield a score between zero and 40 , and the total rating score for each individual study was reported. Any disagreement on the risk of bias assessment was resolved after consulting a third author (R.N.). The level of agreement between the two review authors was assessed with Cohen kappa statistics.

A sensitivity analysis was planned for the main outcome by excluding the clinical trial with the higher risk of bias.

\section{Assessment of heterogeneity}

For all analyses, statistical heterogeneity was assessed by the $1^{2}$ index. A value of $0 \%$ indicates no observed heterogeneity, and greater values indicate increasing heterogeneity, with 25\% indicating low, 50\% moderate, and 75\% high heterogeneity.

\section{Assessment of the quality of evidence}

The quality of evidence was evaluated using the Grades of Recommendation, Assessment, Development and Evaluation Pro software (GRADEPro; http://www. gradepro.org/). ${ }^{36}$ This assessment consists of five aspects for overall risk of bias: directness of the evidence, consistency of the results, precision of the estimates, risk of publication bias, and magnitude of the effect. The quality of evidence was classified as high, moderate, low, or very low.

Strength of Recommendation Taxonomy (SORT) $)^{37}$ grading system was used to evaluate the strength of recommendation for each outcome analyzed. This tool addresses the issue of patient-oriented (effectiveness) versus disease-oriented evidence (efficacy) and is based on the quality of the individual studies and the consistency of evidence across the studies included in the meta-analyses. The strength of recommendation was graded as A (good-quality patient-oriented evidence), B (limited-quality patient-oriented), and C (disease-oriented evidence).

\section{Selection of studies}

Keyword strategy and electronic search results for all searched databases are reported in Supplementary Table 1. The following information has been provided for each search: electronic database, date of search, search strategy, and number of retrieved items. Among the 6,046 initial identified articles, 2,528 remained after the removal of duplicates. A total of 2,346 articles were excluded on the basis of the title and abstract; of the remaining 182 articles, 162 were excluded after evaluation of their full texts. Of the remaining potentially appropriate trials, 18 articles were identified as eligible to be included in qualitative and quantitative final synthesis. ${ }^{9-26}$ The compete flow diagram of included studies designed according to the PRISMA guideline is provided in Figure 1.

\section{RESULTS}

\section{Study characteristics}

The characteristics of the 18 case series clinical trials included in the meta-analysis are summarized in Table 1. All selected studies evaluated expansion treatment in growing patients with a maxillary discrepancy. The included clinical trials were mainly conducted in a university setting. All studies included both male and female subjects.

\section{Outcome selection and data points}

In total, six main outcomes were investigated for assessment of the dentoskeletal changes induced by 


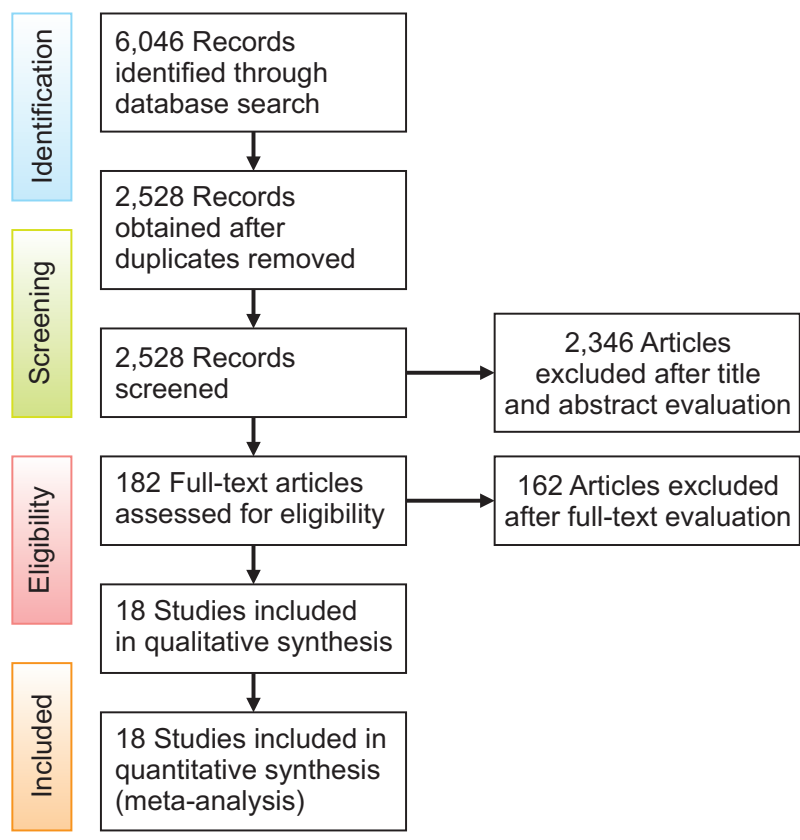

Figure 1. Flow diagram of included studies according to the PRISMA guidelines.

orthopedic maxillary expansion: nasal cavity width, maxillary basal bone width, alveolar buccal crest width, alveolar palatal crest width, inter-molar crown width, inter-molar root apex width, and buccopalatal molar inclination. All the outcomes were evaluated in coronal scans positioned anteroposteriorly at the level of the first molar and were defined as follows: maxillary basal bone width outcome included measurements assessing the horizontal distance between two symmetric points (right/ left) vertically located in the area of the maxillary basal bone and nasal floor (since we considered the increment at specific time points for data synthesis, we were able to group different measurements performed by using reference points that were not necessarily homologous among the selected studies); alveolar buccal crest width included measurements assessing the distance between the most coronal right and left maxillary vestibular alveolar crest; alveolar palatal crest width included measurements assessing the distance between the most coronal right and left maxillary palatal alveolar crest; interdental width included measurements assessing the inter-molar distance (right-left) measured both in the dental crown (cusps, occlusal groove, pulp chamber) and in the radicular portion (radicular apex, middle third root area); buccopalatal molar inclination included measurements assessing the variation of the angle obtained by the intersection of tooth axis and reference lines; and nasal cavity width included measurements assessing the horizontal distance between the right- and left-most lateral points of the nasal cavity.
All considered trials performed a pre-expansion evaluation of considered outcomes $\left(T_{0}\right)$. Twelve trials performed a second outcome evaluation at the end of the active expansion period $\left(T_{1}\right)$, in a time interval between 2 and 6 weeks. Nine trials performed an outcome evaluation at the end of the retention period $\left(T_{2}\right)$, in a time interval between 4 and 8 months. Four trials performed both $\mathrm{T}_{1}$ and $\mathrm{T}_{2}$ outcome evaluations. After pooling data extracted from all considered trials, the total number of patients considered for the time interval $T_{1}-T_{0}$ were as follows: 160 subjects for nasal cavity width; 135 subjects for basal bone molars; 182 subjects for alveolar buccal crest; 63 subjects for alveolar palatal crest; 179 subjects for molar crown interdental width; 152 subjects for molar root interdental width; and 122 subjects for dental tipping. The total number of patients considered for the time interval $T_{2}-T_{0}$ were as follows: 25 subjects for nasal cavity width; 126 subjects for basal bone molars; 62 treated subjects for alveolar buccal crest; 117 subjects for alveolar palatal crest; 232 subjects for molar interdental width crown; 93 subjects for molar root interdental width; and 37 treated subjects for dental tipping.

\section{Assessment of risk of bias}

Supplementary Table 2 reports the risk of bias evaluation performed with a tool specifically designed for case series uncontrolled trials (i.e., Moga's tool). The tool provides no cut-off scores to classify high or low risk of bias. However, evaluation of the results of this tool could help readers to understand the methodological quality of the included studies. The trials exhibited comprehensive risk of bias values ranging from 24 to 32 , with a mean value and standard deviation of 28.7 and \pm 2.8 , respectively. For some questions, the majority of trials obtained a low score. For example, the majority of trials did not report side effects, patients lost to followup, blinding of outcome assessors, and consecutive recruitment. These limitations primarily affected the final scores.

Considering the intrinsic bias of case series, the risk of bias evaluation showed an overall good methodology among the selected studies. The inter-reviewer agreements for study selection, data extraction, and risk of bias assessment were acceptable, with kappa values of $0.92,0.94$, and 0.89 , respectively.

\section{Quantitative data analysis}

Supplementary Figures 1 to 7 report the forest plots obtained by performing quantitative synthesis of maxillary expansion treatment effects from comparing $T_{0}$ (pre-expansion) and $\mathrm{T}_{1}$ (post-expansion) data for all the considered outcomes. Each forest plot reports the included trials, the weights of every considered trial, the 
Table 1. Characteristics of selected studies

\begin{tabular}{|c|c|c|c|c|c|c|c|}
\hline Study & $\begin{array}{c}\text { Sample } \\
\text { size }\end{array}$ & $\begin{array}{l}\text { Mean } \\
\text { age } \\
(\mathrm{yr})\end{array}$ & $\begin{array}{l}\text { Expansion } \\
\text { activation }\end{array}$ & $\begin{array}{l}\text { Amout of } 1 \\
\text { activation } \\
(\mathrm{mm})\end{array}$ & $\begin{array}{l}\text { Activation } \\
\text { period }\end{array}$ & $\begin{array}{c}\text { Retention } \\
\text { period (mo) }\end{array}$ & $\begin{array}{l}\text { Observation } \\
\text { period }\end{array}$ \\
\hline Ballanti et al. ${ }^{9}$ (2009) & 17 & 11 & 2 a day & 0.25 & 14 days & 6 & $\mathrm{~T}_{0}, \mathrm{~T}_{1}, \mathrm{~T}_{2}$ \\
\hline Baratieri et al. ${ }^{10}(2010)$ & 17 & 10 & $\begin{array}{l}4 \text { first day, } \\
1 \text { further days }\end{array}$ & 0.25 & $2-3$ weeks & 6 & $\mathrm{~T}_{0}, \mathrm{~T}_{1}, \mathrm{~T}_{2}$ \\
\hline Baysal et al. ${ }^{11}$ (2011) & 20 & 14 & 2 a day & 0.25 & Until correction & 6 & $\mathrm{~T}_{0}, \mathrm{~T}_{1}, \mathrm{~T}_{2}$ \\
\hline Christie et al. $^{12}(2010)$ & 24 & 10 & 2 a day & 0.25 & 30 days & $\begin{array}{l}\text { No evaluation } \\
\text { after retention }\end{array}$ & $\mathrm{T}_{0}, \mathrm{~T}_{1}$ \\
\hline Cordasco et al. ${ }^{13}$ (2012) & 8 & 10 & $\begin{array}{l}8 \text { first day, } \\
3 \text { further days }\end{array}$ & 0.25 & 12 days & 7 & $\mathrm{~T}_{0}, \mathrm{~T}_{2}$ \\
\hline $\operatorname{Dias}^{14}(2010)$ & 33 & 11 & $\begin{array}{l}4 \text { first day, } \\
2 \text { further days }\end{array}$ & 0.25 & 15 days & 6 & $\mathrm{~T}_{0}, \mathrm{~T}_{1}, \mathrm{~T}_{2}$ \\
\hline Dogra et al. ${ }^{15}(2016)$ & 10 & 14 & 2 a day & 0.20 & $\begin{array}{l}\text { 4-6 weeks until } \\
\text { overcorrection }\end{array}$ & $\begin{array}{l}\text { No evaluation } \\
\text { after retention }\end{array}$ & $\mathrm{T}_{0}, \mathrm{~T}_{1}$ \\
\hline Görgülü et al. ${ }^{16}(2011)$ & 15 & 14 & 2 a day & 0.25 & $\begin{array}{l}\text { Until } \\
\text { overcorrection }\end{array}$ & 6 & $\mathrm{~T}_{0}, \mathrm{~T}_{2}$ \\
\hline Helmkamp $^{17}(2016)$ & 18 & 12.3 & 2 a day & 0.25 & $\begin{array}{l}\text { Until } \\
\text { overcorrection }\end{array}$ & $\begin{array}{l}\text { No evaluation } \\
\text { after retention }\end{array}$ & $\mathrm{T}_{0}, \mathrm{~T}_{1}$ \\
\hline Kanomi et al. ${ }^{18}$ (2013) & 89 & 13 & 2 a day & 0.25 & 10 days & $5-6$ & $\mathrm{~T}_{0}, \mathrm{~T}_{2}$ \\
\hline Li et al. ${ }^{19}(2015)$ & 35 & 17 & 2 a day & 0.25 & 16 days & $\begin{array}{l}\text { No evaluation } \\
\text { at } 4-8\end{array}$ & $\mathrm{~T}_{0}, \mathrm{~T}_{1}$ \\
\hline Luebbert et al..$^{20}(2016)$ & 41 & 10 & 2 a day & $\begin{array}{c}0.25 \\
\left(1^{\circ} \text { group }\right) \\
0.40 \\
\left(2^{\circ} \text { group }\right)\end{array}$ & $\begin{array}{l}\text { Until } \\
\text { overcorrection }\end{array}$ & $\begin{array}{l}6\left(1^{\circ} \text { group }\right) \\
4\left(2^{\circ} \text { group }\right)\end{array}$ & $\mathrm{T}_{0}, \mathrm{~T}_{2}$ \\
\hline Martins $^{21}(2011)$ & 8 & 12 & 2 a day & 0.25 & $\begin{array}{l}\text { Until } \\
\text { overcorrection }\end{array}$ & 5 & $\mathrm{~T}_{0}, \mathrm{~T}_{2}$ \\
\hline Mosleh et al. $^{22}$ (2015) & 10 & 12 & 2 a day & 0.25 & 11 days & $\begin{array}{l}\text { No evaluation } \\
\text { after retention }\end{array}$ & $\mathrm{T}_{0}, \mathrm{~T}_{1}$ \\
\hline $\begin{array}{l}\text { Pangrazio-Kulbersh } \\
\text { et al. }^{23}(2012)\end{array}$ & 23 & 13 & 1 a day & 0.25 & 4-6 weeks & $\begin{array}{l}\text { No evaluation } \\
\text { after retention }\end{array}$ & $\mathrm{T}_{0}, \mathrm{~T}_{1}$ \\
\hline Podesser et al. ${ }^{24}$ (2007) & 9 & 11 & 2 a day & 0.25 & 14 days & $\begin{array}{l}\text { No evaluation } \\
\text { after retention }\end{array}$ & $\mathrm{T}_{0}, \mathrm{~T}_{1}$ \\
\hline $\operatorname{Rocco}^{25}(2012)$ & 22 & 12.8 & $\begin{array}{l}4 \text { first day, } \\
2 \text { further days }\end{array}$ & 0.20 & $\begin{array}{l}\text { Until } \\
\text { overcorrection }\end{array}$ & $\begin{array}{l}\text { No evaluation } \\
\text { after retention }\end{array}$ & $\mathrm{T}_{0}, \mathrm{~T}_{1}$ \\
\hline $\begin{array}{l}\text { Weissheimer et al. }{ }^{26} \\
(2011)\end{array}$ & 33 & 12 & $\begin{array}{l}4 \text { first day, } \\
2 \text { further days }\end{array}$ & 0.20 & 19 days & $\begin{array}{l}\text { No evaluation } \\
\text { after retention }\end{array}$ & $\mathrm{T}_{0}, \mathrm{~T}_{1}$ \\
\hline
\end{tabular}

$\mathrm{T}_{0}$, Pre-expansion; $\mathrm{T}_{1}$, post-expansion; $\mathrm{T}_{2}$, post-retention.

MDs of treatment effects, the corresponding 95\% Cls, the significance $(p)$, and the heterogeneity $\left(1^{2} \%\right)$.

All the investigated outcomes showed statistically significant differences at the end of active expansion: maxillary basal bone width, $+2.46 \mathrm{~mm}(95 \% \mathrm{Cl},-1.90-$ 3.02; $\left.p<0.001 ; 1^{2}=90.8 \%\right)$; nasal cavity width, +1.95 mm (95\% Cl, 1.30-2.59; $\left.p<0.001 ; l^{2}=81.3 \%\right)$; alveolar buccal crest width, $+3.90 \mathrm{~mm}(95 \% \mathrm{Cl}, 2.95-4.84 ; p$ $\left.<0.001 ; 1^{2}=95.8 \%\right)$; alveolar palatal crest width, +3.09 $\mathrm{mm}\left(95 \% \mathrm{Cl}, 1.96-4.21 ; p<0.001 ; 1^{2}=84.7 \%\right)$; inter- molar crown width, $+5.69 \mathrm{~mm}(95 \% \mathrm{Cl}, 4.13-7.26 ; p<$ $\left.0.001 ; 1^{2}=98.7 \%\right)$; inter-molar root apex width, +2.85 $\mathrm{mm}\left(95 \% \mathrm{Cl}, 2.51-3.20 ; p<0.05 ; 1^{2}=62.8 \%\right)$; and dental tipping, $+3.75^{\circ}\left(95 \% \mathrm{Cl}, 2.18-5.31 ; p<0.001 ; 1^{2}\right.$ $=94.4 \%)$.

Supplementary Figures from 8 to 14 report the forest plots obtained by performing quantitative synthesis of maxillary expansion treatment effects when comparing $\mathrm{T}_{0}$ (pre-expansion) and $\mathrm{T}_{2}$ (post-retention) for all the considered outcomes. 
All the investigated outcomes showed statistically significant differences at $T_{2}$ (post-retention) compared to the $\mathrm{T}_{0}$ (pre-expansion) condition: maxillary basal bone width, $+2.21 \mathrm{~mm}\left(95 \% \mathrm{Cl}, 1.48-2.93 ; p<0.001 ; 1^{2}=\right.$ 91.9\%); nasal cavity width, $+1.55 \mathrm{~mm}(95 \% \mathrm{Cl},-0.29-$ 3.39; $\left.p<0.05 ; 1^{2}=90.08 \%\right)$; alveolar buccal crest width, +3.57 mm $\left(95 \% \mathrm{Cl}, 2.10-5.04 ; p<0.001 ; 1^{2}=\right.$ 94.6\%); alveolar palatal crest width, $+3.32 \mathrm{~mm}(95 \% \mathrm{Cl}$, 2.70-3.94; $\left.p<0.001 ; 1^{2}=93.9 \%\right)$; inter-molar crown width, +5.43 mm $\left(95 \% \mathrm{Cl}, 4.34-6.51 ; p<0.001 ; 1^{2}=\right.$ 96.0\%); inter-molar root apex width, $+4.75 \mathrm{~mm}(95 \%$ $\left.\mathrm{Cl}, 3.49-6.01 ; p<0.001 ; 1^{2}=97.0 \%\right)$; dental tipping, $2.22^{\circ}\left(95 \% \mathrm{Cl}, 1.58-2.86 ; p>0.05 ; 1^{2}=29.4 \%\right)$.

Statistical heterogeneity was high, showing an average value of $86.81 \%$ for the post-expansion evaluation $\left(\mathrm{T}_{1}-\mathrm{T}_{0}\right)$ and an average value of $84.80 \%$ for the postretention evaluation $\left(\mathrm{T}_{2}-\mathrm{T}_{0}\right)$. The observed statistical heterogeneity could be related to the clinical heterogeneity across the considered studies. The studies showed differences in terms of average sample age and expansion protocol, and even though all trials performed a RME protocol and ended appliance activation within six weeks from the first appliance activation, they reported different numbers of activations per day and different active expansion treatment durations. Supplementary Figure 15 reports the results of the sensitivity analysis.

Table 2 provides a summary of all outcomes evaluated with a meta-analytic approach. For each outcome, it reports the number of studies, the computed effect size, the $95 \% \mathrm{Cl}, \mathrm{l}^{2}$ values, and the level of significance.

\section{Assessment of quality of evidence}

According to the GRADE, ${ }^{36}$ there was a very low level of evidence to support the successful use of orthopedic palatal expansion in treating skeletal transverse maxillary deficiency (Supplementary Table 3). However, it is well known that RME can clinically correct a transverse maxillary deficiency. ${ }^{4,-9}$ This inconsistency between clinical outcomes and scientific evidence is related to the absence of published clinical trials with low risk of bias for ethical reasons (i.e., randomized or controlled clinical trials). In fact, in order to obtain an untreated control group, it would be necessary to expose the untreated growing patients to two CT examinations in a short period of time, which is ethically not acceptable.

However, it is important to determine the precise amount of skeletal expansion that can be obtained with the maxillary expansion procedure as well as the dentoalveolar compensation that this procedure causes. This systematic review with meta-analysis represents the gold standard for this information, even though it was conducted by including potentially biased case series.

According to the SORT approach ${ }^{37}$ the strength of recommendation was classified as C (patient-oriented outcome) for all evaluated outcomes. We categorized all the outcomes investigated as patient-oriented level, since all of them ultimately affect the occlusion, smile esthetics, and functionality of the entire oral apparatus; however,

Table 2. Computed mean difference for each evaluated outcome

\begin{tabular}{|c|c|c|c|c|c|c|}
\hline & Outcome & $\begin{array}{c}\text { No. of } \\
\text { studies }\end{array}$ & $\begin{array}{l}\text { Effect } \\
\text { size }\end{array}$ & $\begin{array}{c}95 \% \text { confidence } \\
\text { interval }\end{array}$ & I-squared (\%) & $p$-value \\
\hline \multirow[t]{7}{*}{$\mathrm{T}_{0}-\mathrm{T}_{1}$} & Maxillary basal bone width & 7 & 2.46 & $1.90-3.02$ & 90.8 & $<0.001$ \\
\hline & Nasal cavity width & 8 & 1.95 & $1.30-2.59$ & 81.3 & $<0.001$ \\
\hline & Alveolar buccal crest width & 9 & 3.90 & $2.95-4.84$ & 95.8 & $<0.001$ \\
\hline & Alveolar palatal crest width & 4 & 3.09 & $1.96-4.21$ & 84.7 & $<0.001$ \\
\hline & Inter-molars crown width & 9 & 5.69 & $4.13-7.26$ & 98.7 & $<0.001$ \\
\hline & Inter-molars root apex width & 7 & 2.85 & $2.51-3.20$ & 62.8 & 0.013 \\
\hline & Dental tipping & 6 & 3.75 & $2.18-5.31$ & 94.4 & $<0.001$ \\
\hline \multirow[t]{7}{*}{$\mathrm{T}_{0}-\mathrm{T}_{2}$} & Maxillary basal bone width & 7 & 2.21 & $1.48-2.93$ & 91.9 & $<0.001$ \\
\hline & Nasal cavity width & 2 & 1.55 & $0.29-3.39$ & 90.8 & $<0.001$ \\
\hline & Alveolar buccal crest width & 4 & 3.57 & $2.10-5.04$ & 94.6 & $<0.001$ \\
\hline & Alveolar palatal crest width & 3 & 3.32 & $2.70-3.94$ & 93.9 & $<0.001$ \\
\hline & Inter-molars crown width & 9 & 5.43 & $4.34-6.51$ & 96.0 & $<0.001$ \\
\hline & Inter-molars root apex width & 4 & 4.75 & $3.49-6.01$ & 97.0 & $<0.001$ \\
\hline & Dental tipping & 2 & 2.22 & $1.58-2.86$ & 29.4 & 0.234 \\
\hline Sensitivity analysis & Maxillary basal bone width & 6 & 2.43 & $1.85-3.01$ & 92.3 & $<0.001$ \\
\hline
\end{tabular}

Random-effects model was applied to estimate all pooled data.

$\mathrm{T}_{0}$, Pre-expansion; $\mathrm{T}_{1}$, post-expansion; $\mathrm{T}_{2}$, post-retention. 
Table 3. Strength of recommendation for each outcome investigated in the present study

\begin{tabular}{|c|c|c|c|c|}
\hline Outcome & $\begin{array}{c}\text { Study } \\
\text { quality* }\end{array}$ & Consistency* & $\begin{array}{l}\text { Strength of } \\
\text { recommendation* }\end{array}$ & Explanation \\
\hline $\begin{array}{l}\text { Maxillary basal } \\
\text { bone width }\end{array}$ & Level 3 & YES & $\mathrm{C}$ & $\begin{array}{l}\text { Patient-oriented outcome } \\
\text { Meta-analysis including } 7 \text { case series studies }\end{array}$ \\
\hline Nasal cavity width & Level 3 & YES & $\mathrm{C}$ & $\begin{array}{l}\text { Patient-oriented outcome } \\
\text { Meta-analysis including } 8 \text { case series studies }\end{array}$ \\
\hline $\begin{array}{l}\text { Alveolar buccal } \\
\text { crest width }\end{array}$ & Level 3 & YES & $\mathrm{C}$ & $\begin{array}{l}\text { Patient-oriented outcome } \\
\text { Meta-analysis including } 9 \text { case series studies }\end{array}$ \\
\hline $\begin{array}{l}\text { Alveolar palatal } \\
\text { crest width }\end{array}$ & Level 3 & YES & $\mathrm{C}$ & $\begin{array}{l}\text { Disease-oriented outcome } \\
\text { Meta-analysis including } 4 \text { case series studies }\end{array}$ \\
\hline $\begin{array}{l}\text { Inter-molars } \\
\text { crown width }\end{array}$ & Level 3 & YES & $\mathrm{C}$ & $\begin{array}{l}\text { Patient-oriented outcome } \\
\text { Meta-analysis including } 9 \text { case series studies }\end{array}$ \\
\hline $\begin{array}{l}\text { Inter-molars root } \\
\text { apex width }\end{array}$ & Level 3 & YES & $\mathrm{C}$ & $\begin{array}{l}\text { Disease-oriented outcome } \\
\text { Meta-analysis including } 7 \text { case series studies }\end{array}$ \\
\hline Dental tipping & Level 3 & YES & $\mathrm{C}$ & $\begin{array}{l}\text { Patient-oriented outcome } \\
\text { Meta-analysis including } 6 \text { case series studies }\end{array}$ \\
\hline
\end{tabular}

*Reports of levels of study quality, consistency of measured outcomes, and strength of recommendation according to the Strength of Recommendation Taxonomy system.

the methodological design of all included studies, i.e., the absence of a control group, negatively affected the final judgment for the strength of recommendation (Table 3).

Supplementary data is available at http://doi. org/10.4041/kjod.2020.50.5.314.

\section{DISCUSSION}

To the best of our knowledge, this is the first review with a meta-analysis that assesses the short-term treatment effects of RME with the accuracy and 3D imaging afforded by CT. The results of this meta-analysis confirm that RME produces a transverse skeletal increment of the basal palatal bone $(+2.46 \mathrm{~mm})$, nasal cavity $(+1.95$ $\mathrm{mm})$, alveolar buccal bone $(+3.9 \mathrm{~mm})$, and alveolar palatal bone $(+3.09 \mathrm{~mm})$ in the molar region after the active expansion period. Specifically, the transverse increment in the nasal cavity is lower than that at the basal bone level, which is also lower than the increment at the alveolar bone level. This datum confirmed the conclusions of previous studies ${ }^{5,24}$ that described the presence of a positive expansion gradient from the cranial to the caudal region of the maxilla.

At 4-8 months after the end of the retention period, all skeletal increments obtained after the active expansion period showed relapse ranging from $8 \%$ to $20 \%$. This skeletal relapse showed a negative cranio-caudal gradient. In fact, the results showed the highest relapse at the nasal cavity level (-20\%; from 1.95 to $1.55 \mathrm{~mm}$ ), an intermediate relapse at the maxillary basal bone level (-10\%; from 2.45 to $2.21 \mathrm{~mm})$, a lower relapse at the alveolar buccal bone level (-8\%; from 3.9 to $3.57 \mathrm{~mm})$, and an increment at the alveolar palatal bone level $(+7 \%$; from 3.09 to $3.32 \mathrm{~mm}$ ).

The dental outcomes showed that the expansion procedure produces a crown expansion of $5.69 \mathrm{~mm}$ in the molar region after the active expansion period, and this result confirms the capacity of RME treatment to successfully correct a dental posterior cross-bite. ${ }^{11,13,16,17}$ At the end of the active expansion period $\left(T_{1}\right)$, data showed that the average root apex expansion was $2.85 \mathrm{~mm}$; this amount of expansion was almost half of the expansion at the crown level, revealing a vestibulo-oral inclination of the maxillary molar. This result is confirmed by the angular outcome, which evaluated the vestibular inclination of molars and showed an average increment of $+3.75^{\circ}$ per side after the active expansion period.

These changes in molar inclination could be responsible for the creation of maxillo-mandibular dental precontacts and could explain some authors' observations that a downward movement of the mandible occurred immediately after the active phase of RME. ${ }^{38}$ After the retention period, the molar crown increment obtained at the end of expansion was essentially maintained, with a small reduction varying from $5.69 \mathrm{~mm}$ to $5.43 \mathrm{~mm}$. Data showed that first molar root expansion exhibited a significant increase during the retention period $(+66 \%$; from 2.85 to $4.75 \mathrm{~mm}$ ) and the first molar axial angle shows a considerable reduction $\left(-41 \%\right.$; from $3.75^{\circ}$ to $2.22^{\circ}$ ). These findings may indicate the presence of a couple force system exerted on each anchor molar by the palatal expander and its bands after the active expansion phase. We speculated that immediately after the 
expansion phase, the expander would incorporate a potential energy that could cause vestibulolingual root uprighting during the retention period. By this mechanism, molar roots could return, during the retention phase, to their pre-treatment vestibulolingual inclination.

The results of this meta-analysis offer interesting data for the ratio expressed as a percentage between skeletal and dental expansion. Using the values of dental molar and basal bone expansion, the percentage of skeletal expansion in comparison to dental expansion was calculated. After the active expansion period, the skeletal expansion was $43 \%$ of the dental expansion $(2.46 \mathrm{~mm}$ of skeletal basal increment and $5.69 \mathrm{~mm}$ of molar expansion); after 6-8 months of retention, the skeletal expansion was $41 \%$ of the dental expansion $(2.21 \mathrm{~mm}$ of skeletal basal increment and $5.43 \mathrm{~mm}$ of molar expansion).

Skeletal relapse occurring after palatal skeletal expansion has been previously described ${ }^{39}$ as a re-jointing process of the two maxillary bones that occurs despite the palatal expander acting as a fixed molar retainer, when the maxillae move through the molars. Our data seems to confirm this hypothesis, with a reduction in transverse dimension during the retention phase of palatal expansion for all the considered parameters. However, the amount of skeletal relapse is limited, according to our results, with the data clearly showing that the majority of skeletal improvement is maintained after the retention phase.

The limitations of this systematic review with metaanalysis are related to the design of the selected studies, since case series have intrinsic biases related to absence of an untreated control group in their design. However, during the relatively short time of observation of 6-8 months, we can consider the maxillary growth to be almost negligible.

However, in order to properly evaluate the results of this meta-analysis, it is important to consider that the amount of reported transverse skeletal increment could be slightly overestimated considering the transverse skeletal growth of subjects included in the considered trials. Longitudinal studies ${ }^{31}$ evaluating postero-anterior cephalograms for transverse maxillary growth by means of metallic implants showed that transverse growth in the posterior maxilla is $0.29 \mathrm{~mm} /$ year $(p<0.001 ; 95 \%$ $\mathrm{Cl}, 0.26-0.33)$. The maximum considered observation interval of this review was 6-8 months. Incorporating the previous reported datum of $0.29 \mathrm{~mm} /$ year for maxillary growth to our maximum considered interval, it is possible to estimate the amount of transverse maxillary growth with the results of our meta-analysis. According to our calculation data, palatal expansion at 6 and 8 months could promote 0.17 and $0.23 \mathrm{~mm}$ of maxillary growth, respectively. It is important to consider these values while interpreting the results of this review article in order to partially limit data misinterpretation related to the bias of the included trials. The review did not evaluate the long-term evaluation modifications occurring after 8 months, because after this period of time the impact of growth would have been more important.

Finally, a sensitivity analysis was performed for the main outcome (maxillary basal bone width) after the active expansion phase $\left(T_{1}-T_{0}\right)$ while excluding the trial by Dogra et al., ${ }^{15}$ which showed a higher risk of bias. The sensitivity analysis showed similar results as the corresponding complete analysis, thus confirming the results of the overall meta-analysis.

\section{CONCLUSION}

- RME produces skeletal and dental treatment effects. The skeletal expansion measured at the basal bone level in first molar region $(+2.21 \mathrm{~mm})$ at the end of the retention period was $41 \%$ of the dental expansion $(+5.43$ $\mathrm{mm})$.

- Skeletal expansion of the nasomaxillary complex was greater in caudal maxillary structures than cranial structures.

- Maxillary basal bone showed 10\% post-retention relapse.

- Dental expansion causes, during the active phase of expansion, a buccal movement of the first molar crown with a vestibulolingual inclination increase, during the retention period it was observed a vestibulolingual root up-righting, by this movement molar roots almost return to their pre-treatment inclination.

\section{CONFLICTS OF INTEREST}

No potential conflict of interest relevant to this article was reported.

\section{REFERENCES}

1. Angell DH. Treatment of irregularity of the permanent or adult teeth. Dent Cosmos 1860;1:540-4.

2. Haas AJ. Palatal expansion: just the beginning of dentofacial orthopedics. Am J Orthod 1970;57:21955.

3. Lo Giudice A, Fastuca R, Portelli M, Militi A, Bellocchio M, Spinuzza P, et al. Effects of rapid vs slow maxillary expansion on nasal cavity dimensions in growing subjects: a methodological and reproducibility study. Eur J Paediatr Dent 2017;18:299-304.

4. Lo Giudice A, Barbato E, Cosentino L, Ferraro CM, Leonardi R. Alveolar bone changes after rapid maxillary expansion with tooth-born appliances: a systematic review. Eur J Orthod 2018;40:296-303. 
5. Wertz RA. Skeletal and dental changes accompanying rapid midpalatal suture opening. Am J Orthod 1970;58:41-66.

6. Leonardi R, Annunziata A, Caltabiano M. Landmark identification error in posteroanterior cephalometric radiography. A systematic review. Angle Orthod 2008;78:761-5.

7. Timms DJ, Preston CB, Daly PF. A computed tomographic assessment of maxillary movement induced by rapid expansion - a pilot study. Eur J Orthod 1982;4:123-7.

8. Podesser B, Williams S, Bantleon HP, Imhof H. Quantitation of transverse maxillary dimensions using computed tomography: a methodological and reproducibility study. Eur J Orthod 2004;26:209-15.

9. Ballanti F, Lione R, Fanucci E, Franchi L, Baccetti T, Cozza P. Immediate and post-retention effects of rapid maxillary expansion investigated by computed tomography in growing patients. Angle Orthod 2009;79:24-9.

10. Baratieri C, Nojima Ll, Alves M Jr, Gomes de Souza MM, Gonçalves Nojima M. Transverse effects of rapid maxillary expansion in Class 11 malocclusion patients: a Cone-Beam Computed Tomography study. Dental Press J Orthod 2010;15:89-97.

11. Baysal A, Veli 1, Ucar Fl, Eruz M, Ozer T, Uysal T. Changes in mandibular transversal arch dimensions after rapid maxillary expansion procedure assessed through Cone-Beam Computed Tomography. Korean J Orthod 2011;41:200-10.

12. Christie KF, Boucher N, Chung CH. Effects of bonded rapid palatal expansion on the transverse dimensions of the maxilla: a Cone-Beam Computed Tomography study. Am J Orthod Dentofacial Orthop 2010;137(4 Suppl):S79-85.

13. Cordasco G, Nucera R, Fastuca R, Matarese G, Lindauer SJ, Leone P, et al. Effects of orthopedic maxillary expansion on nasal cavity size in growing subjects: a low dose computer tomography clinical trial. Int J Pediatr Otorhinolaryngol 2012;76:154751.

14. Dias LS. Avaliação pós-expansão rápida da maxila com aparelhos do tipo Haas e Hyrax por meio de tomografia computadorizada cone beam [MD thesis]. Porto Alegre: Pontifícia Universidade Católica do Rio Grande do Sul; 2010.

15. Dogra N, Sidhu MS, Dabas A, Grover S, Gupta M. Cone-Beam Computed Tomography evaluation of dental, skeletal, and alveolar bone changes associated with bonded rapid maxillary expansion. J Indian Orthod Soc 2016;50:19-25.

16. Görgülü S, Gokce SM, Olmez H, Sagdic D, Ors F. Nasal cavity volume changes after rapid maxillary expansion in adolescents evaluated with 3-dimen- sional simulation and modeling programs. Am J Orthod Dentofacial Orthop 2011;140:633-40.

17. Helmkamp ME. Three-dimensional evaluation of implant-supported rapid maxillary expansion vs. traditional tooth-borne rapid maxillary expansion using Cone-Beam Computed Tomography [MD thesis]. St. Louis: St. Louis University; 2016.

18. Kanomi R, Deguchi T, Kakuno E, Takano-Yamamoto T, Roberts WE. CBCT of skeletal changes following rapid maxillary expansion to increase arch-length with a development-dependent bonded or banded appliance. Angle Orthod 2013;83:851-7.

19. Li L, Qi S, Wang H, Ren S, Ban J. Cone-Beam Computed Tomography analysis of effects of rapid maxillary expansion on cranio maxillo-facial bones and upper airway. Honghua Xi Kou Qiang Yi Xue Za Zhi 2015;50:403-7.

20. Luebbert J, Ghoneima A, Lagravère MO. Skeletal and dental effects of rapid maxillary expansion assessed through three-dimensional imaging: A multicenter study. Int Orthod 2016;14:15-31.

21. Martins LP. Análise dos resultados do tratamento da mordida cruzada posterior funcional com o expansor fixo hyrax [MD thesis]. San Pablo: Universidade Estadual Paulista; 2011.

22. Mosleh Ml, Kaddah MA, Abd ElSayed FA, ElSayed HS. Comparison of transverse changes during maxillary expansion with 4-point bone-borne and toothborne maxillary expanders. Am J Orthod Dentofacial Orthop 2015;148:599-607.

23. Pangrazio-Kulbersh V, Wine P, Haughey M, Pajtas B, Kaczynski R. Cone Beam Computed Tomography evaluation of changes in the naso-maxillary complex associated with two types of maxillary expanders. Angle Orthod 2012;82:448-57.

24. Podesser B, Williams S, Crismani AG, Bantleon HP. Evaluation of the effects of rapid maxillary expansion in growing children using computer tomography scanning: a pilot study. Eur J Orthod 2007;29:37-44.

25. Rocco MA. Avaliação dos efeitos da expansão rápida da maxila no volume aéreo nasal, por meio da tomografia computadorizada de feixe cônico [PhD dissertation]. San Pablo: Universidade Estadual Paulista; 2012.

26. Weissheimer A, de Menezes LM, Mezomo M, Dias DM, de Lima EM, Rizzatto SM. Immediate effects of rapid maxillary expansion with c-type and hyraxtype expanders: a randomized clinical trial. Am J Orthod Dentofacial Orthop 2011;140:366-76.

27. Schiffman PH, Tuncay OC. Maxillary expansion: a meta analysis. Clin Orthod Res 2001;4:86-96.

28. Lagravère MO, Heo G, Major PW, Flores-Mir C. Meta-analysis of immediate changes with rapid 
maxillary expansion treatment. J Am Dent Assoc 2006;137:44-53.

29. Zhou Y, Long H, Ye N, Xue J, Yang X, Liao L, et al. The effectiveness of non-surgical maxillary expansion: a meta-analysis. Eur J Orthod 2014;36:23342.

30. Liberati A, Altman DG, Tetzlaff J, Mulrow C, Gøtzsche PC, loannidis JP, et al. The PRISMA statement for reporting systematic reviews and metaanalyses of studies that evaluate health care interventions: explanation and elaboration. J Clin Epidemiol 2009;62:e1-34.

31. Korn EL, Baumrind S. Transverse development of the human jaws between the ages of 8.5 and 15.5 years, studied longitudinally with use of implants. J Dent Res 1990;69:1298-306.

32. Chambers D, Rodgers M, Woolacott N. Not only randomized controlled trials, but also case series should be considered in systematic reviews of rapidly developing technologies. J Clin Epidemiol 2009;62:125360.e4.

33. Dalziel K, Round A, Stein K, Garside R, Castelnuovo E, Payne $L$. Do the findings of case series studies vary significantly according to methodological characteristics? Health Technol Assess 2005;9:iii-iv, 1-146.
34. Fitzpatrick-Lewis D, Ciliska D, Thomas H. The methods for the synthesis of studies without control groups. Hamilton: National Collaborating Centre for Methods and Tools; 2009.

35. Guo B, Moga C, Harstall C, Schopflocher D. A principal component analysis is conducted for a case series quality appraisal checklist. J Clin Epidemiol 2016;69:199-207.e2.

36. Guyatt GH, Oxman AD, Vist GE, Kunz R, Falck-Ytter Y, Alonso-Coello P, et al. GRADE: an emerging consensus on rating quality of evidence and strength of recommendations. BMJ 2008;336:924-6.

37. Newman MG, Weyant R, Hujoel P. JEBDP improves grading system and adopts strength of recommendation taxonomy grading (SORT) for guidelines and systematic reviews. J Evid Based Dent Pract 2007;7:147-50.

38. Baratieri C, Alves M Jr, Bolognese AM, Nojima MC, Nojima Ll. Changes in skeletal and dental relationship in Class 11 Division 1 malocclusion after rapid maxillary expansion: a prospective study. Dental Press J Orthod 2014;19:75-81.

39. Brandt S. JCO interviews Dr. Andrew J. Haas. J Clin Orthod 1973;7:227-34. 